\title{
Allied Health Professionals Experience of Supervising Allied Health Assistants. A Mixed Method Study.
}

\author{
Patrick F. Brown \\ Illawarra Shoalhaven Local Health District, pat.brown@health.nsw.gov.au \\ Sue Fitzpatrick \\ Illawarra Shoalhaven Local Health District, sue.fitzpatrick@health.nsw.gov.au \\ Rowena Hockings \\ Illawarra Shoalhaven Local Health District, rowena.hockings@health.nsw.gov.au
}

Follow this and additional works at: https://nsuworks.nova.edu/ijahsp

Part of the Medicine and Health Sciences Commons

\section{Recommended Citation}

Brown PF, Fitzpatrick S, Hockings R. Allied Health Professionals Experience of Supervising Allied Health Assistants. A Mixed Method Study.. The Internet Journal of Allied Health Sciences and Practice. 2020 Jan 01;18(3), Article 6.

This Manuscript is brought to you for free and open access by the College of Health Care Sciences at NSUWorks. It has been accepted for inclusion in Internet Journal of Allied Health Sciences and Practice by an authorized editor of NSUWorks. For more information, please contact nsuworks@nova.edu. 


\title{
Allied Health Professionals Experience of Supervising Allied Health Assistants. A Mixed Method Study.
}

\begin{abstract}
Purpose: The aim of this paper is to quantify time spent by allied health professionals in allied health assistant supervision and to explore allied health assistant supervision from an allied health professional perspective. Method: A convergent parallel mixed method design was used. Forty-seven allied health professionals were surveyed, and 18 allied health professionals participated in focus groups, providing different but complementary data with the aim of gaining a more complete understanding of allied health assistant supervision load. Results: Allied health professionals report spending $10 \%$ of their workday supervising allied health assistants. Descriptive interpretation of the focus group data presents evidence that allied health professionals in this local health district lacked knowledge of allied health assistant training, skills, and roles, and that this gap in understanding affected their ability to supervise and delegate to allied health assistants. Conclusion: The findings were found to support improving knowledge and skills of allied health professionals relating to supervision of allied health assistants.
\end{abstract}

\section{Author Bio(s)}

Patrick Brown is the Allied Health Assistant and Workplace Flexibility Coordinator for the Illawarra Shoalhaven Local Health District. He is a registered Physiotherapist in the state of NSW, Australia and works in private practice.

Dr Sue Fitzpatrick is the Executive Director of allied Health for Illawarra Shoalhaven Local Health District. She is a registered Speech Pathologist in the state of New South Wales, Australia.

Rowena Hockey is a Senior Community Physiotherapist in the Illawarra Shoalhaven Local Health District. She is a registered Physiotherapist in the state of New South Wales, Australia. 


\title{
The Internet Joumnal of Allied Health Sciences and Practice
}

Dedicated to allied health professional practice and education

Vol. 18 No. 3 ISSN 1540-580X

\section{Allied Health Professionals Experience of Supervising Allied Health Assistants: A Mixed Method Study.}

\author{
Patrick F. Brown \\ Sue Fitzpatrick \\ Rowena Hockey \\ Illawarra Shoalhaven Local Health District
}

Australia

\begin{abstract}
Purpose: The aim of this paper is to quantify time spent by allied health professionals in allied health assistant supervision and to explore allied health assistant supervision from an allied health professional perspective. Method: A convergent parallel mixed method design was used. Forty-seven allied health professionals were surveyed, and 18 allied health professionals participated in focus groups, providing different but complementary data with the aim of gaining a more complete understanding of allied health assistant supervision load. Results: Allied health professionals report spending $10 \%$ of their workday supervising allied health assistants. Descriptive interpretation of the focus group data presents evidence that allied health professionals in this local health district lacked knowledge of allied health assistant training, skills, and roles, and that this gap in understanding affected their ability to supervise and delegate to allied health assistants. Conclusion: The findings were found to support improving knowledge and skills of allied health professionals relating to supervision of allied health assistants.
\end{abstract}

Keywords: allied health professional, allied health assistant, supervision 


\section{INTRODUCTION}

Impetus for improved use of the allied health assistant (AHA) workforce has resulted from systemic pressures faced by all Australian public hospitals, such as rising demand, escalating costs, and workforce shortages in key areas. ${ }^{1}$ Evidence for the potential of this workforce to improve service capacity has been linked with calls for greater use of AHAs in various Australian Healthcare settings. ${ }^{3-5}$ This need is highlighted in a 2017 study across participating sites in Victoria, which found that $24 \%$ of allied health professionals' (AHPs) time was spent undertaking tasks that could be performed by AHAs with relevant training and adequate supervision. ${ }^{6}$ AHAs have been defined as persons employed under the supervision of an Allied Health Professional (AHP) who is required to assist with therapeutic and program related activities. ${ }^{7}$ Historically, growth of this workforce has occurred organically and without regulation. ${ }^{8}$ More recently, state industrial awards have been changed to strengthen the link between educational attainment and scope of practice while development of several state AHA frameworks have recognized the need to improve governance relating to this workforce in Australia. ${ }^{7,9,10,11}$ Each of the AHA state frameworks includes sections that provide guidance for supervision of AHAs. This guidance is important, as AHPs are responsible and accountable for the safe completion of clinical tasks delegated to AHAs. ${ }^{12-14}$ The importance of having adequate time for supervision and training of AHA staff is an acknowledged barrier to their increased use. ${ }^{4,5}$ Despite the importance attributed to the role of supervision in each of the Australian frameworks and the relevance of such supervision in the daily work of Allied Health teams, little work has currently been done to quantify or explore AHA supervision from an AHP perspective. The aim of this study was to quantify time spent by AHPs in supervising AHAs and to explore AHAsupervision from an AHP perspective within one health district in southeastern Australia. In so doing, the purpose is to provide data and perspectives not previously reported in academic literature. Furthermore, the aim is that these findings will be useful in supporting local health care organizations to better support the integration of AHAs into the allied health workforce.

\section{METHODS}

A convergent parallel mixed method design was used to gain a more complete understanding of AHA supervision load ${ }^{15}$. A survey was chosen as the most effective and timely means of gathering accurate quantitative data. Focus groups were used to obtain qualitative data and to interpreted using a descriptive qualitative approach. The two separate sets of data were analyzed separately, but then interpreted as one data set to better contrast and corroborate findings ${ }^{15}$ (see Figure 1). Human research ethics approval was gained through the University of Wollongong (HE16/222).

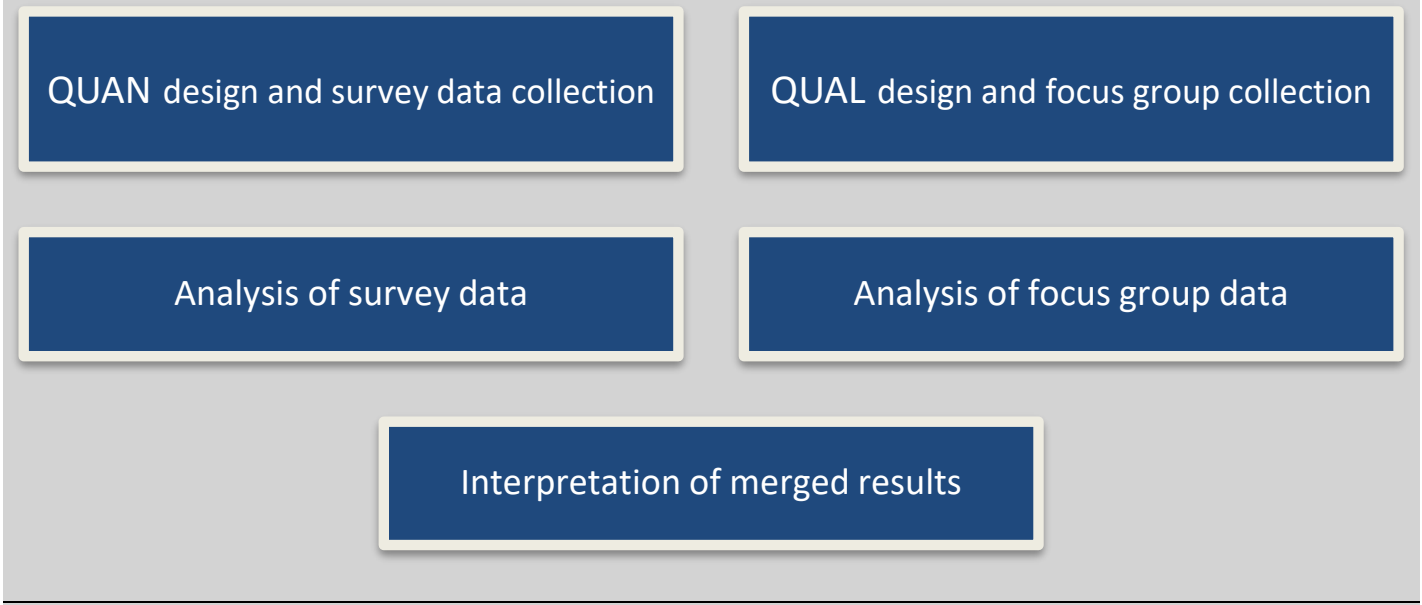

Figure 1: Summary of Mixed Method Design

\section{Participants and Setting}

When this study was conducted, the local health district employed 35 AHAs. Participants for both the survey and focus groups were allied health professionals who supervised at least one AHA. Participants for the survey component of the study were informed of the study using a letter of invitation sent by their unit head. Participation in the study was voluntary. Included in the letter of invitation was information detailing a participant's right to withdraw from the study at any time. Steps to ensure confidentiality were also included. Both paper and online (survey monkey) versions of the survey were made available to AHPs. Participants for the focus group component of the study were also recruited using a letter of invitation from their unit head, sent approximately one month following the survey invitation. AHPs who accepted the focus group invitation did so via email and were asked to sign an informed consent form.

\section{Survey}

The survey contained 19 questions, some of which consisted of a few parts, including both quantitative and qualitative elements. Participants were asked to state their allied health discipline and how many AHAs they supervised in their dayto-day work. Twelve questions related to AHP supervision of AHAs and are included in Table 1. Descriptive statistics have 
been presented as frequencies (percentages) for categorical variables and median (interquartile range) for numerical variables as these variables were not normally distributed. Analysis of the quantitative portion of the survey used STATA statistical software version 13 (StataCorp LP, College Station, Texas). Six of the 19 questions asked for written responses and were grouped thematically and by frequency using Excel spreadsheet software.

Table 1: Survey Questions Pertaining to AHP Supervision of AHAs

\begin{tabular}{|c|l|}
\hline 1 & How many AHAs do you supervise in your day-to-day work? \\
\hline 2 & Are you the designated clinical supervisor for any AHAs? \\
\hline 3 & $\begin{array}{l}\text { If your answer to the previous question was yes, how many AHAs are you the designated clinical } \\
\text { supervisor for? }\end{array}$ \\
\hline 4 & $\begin{array}{l}\text { What amount of your time per day (expressed as hours or part thereof) is dedicated to delegating and } \\
\text { supervising the clinical work of AHAs? }\end{array}$ \\
\hline 5 & Is the amount of time available in your day dedicated to the supervision of AHAs adequate? \\
\hline 6 & $\begin{array}{l}\text { Please comment on your answers in the previous two questions, including what amount of time would } \\
\text { be adequate? }\end{array}$ \\
\hline 7 & Within your workday, are you able to prioritize time for clinical supervision of AHAs? \\
\hline 8 & What helps or hinders your ability to prioritize time for clinical supervision of AHAs. Please comment? \\
\hline 9 & Is your approach to supervising AHAs different to your approach in supervising AHPs? \\
\hline 10 & $\begin{array}{l}\text { Do you feel you have the support of the organization and management to undertake clinical supervision } \\
\text { of AHAs? }\end{array}$ \\
\hline 11 & $\begin{array}{l}\text { Are you comfortable communicating clinical supervision issues relating to AHAS with your operational } \\
\text { manager? }\end{array}$ \\
\hline 12 & Do/does the AHA/s you supervise receive regular formal clinical supervision from you or another AHP? \\
\hline
\end{tabular}

\section{Focus Groups}

Each of the three focus groups involved two of the three researchers and used the same set of 9 focus group questions, developed to explore AHA supervision from an AHP perspective (see Table 2). AHPs in the focus groups were asked about their experience of working with and supervising AHAs, including questions relating to AHP knowledge and skills in supervising AHAs.

Table 2: Focus Group Questions

\begin{tabular}{|c|l|}
\hline 1 & Introductions; what is your experience working with and supervising AHAs? \\
\hline 2 & What amount of your time is spent in supervision of AHAs? Do you believe this is adequate? \\
\hline 3 & What does the time look like when you are supervising an AHA? \\
\hline 4 & $\begin{array}{l}\text { Do you feel you have the support of the organization and management to undertake clinical } \\
\text { supervision of AHAs? }\end{array}$ \\
\hline 5 & Are you able to match your skills and training to adequately supervise AHAs? \\
\hline 6 & $\begin{array}{l}\text { Do you think that AHPs respond to differing levels of experience in AHAs and allocate roles } \\
\text { accordingly? }\end{array}$ \\
\hline 7 & Are there differences in supervising an AHA compared to supervising an AHP? \\
\hline 8 & When would you (hypothetically) delegate tasks? \\
\hline 9 & In what situation(s) would you not (hypothetically) delegate tasks? \\
\hline
\end{tabular}

An audio recording of each of the 3 focus group discussions was made, transcribed verbatim, and then coded so that each participant was de-identified. Thematic analysis of the transcribed focus group content employed a descriptive qualitative approach, built on the assumption that "understanding and interpreting this data are the same endeavor". ${ }^{16}$ Journaling during all stages of the quantitative analysis process served to draw awareness from the researchers regarding their own presuppositions of AHA supervision. ${ }^{16}$ This analysis was conducted by two of the researchers (PB and SF), one of whom (SF) is well practiced in qualitative methodology. ${ }^{17}$

\section{RESULTS}

\section{Quantitative Results}

The online survey was sent to 127 AHPs with supervisory responsibilities to AHAs and was completed by 47 respondents (response rate $37 \%)$. Thirty-eight $(80.9 \%)$ respondents were physiotherapists, $8(17 \%)$ were occupational therapists, and one $(2.1 \%)$ was a speech pathologist. 
Twenty-two (46\%) respondents worked in a rehabilitation setting while fourteen (21\%) worked in an acute setting and 11 $(23 \%)$ worked in community settings. The median (innerquartile range [IRQ]) years worked in their current profession was 8 (3 to 17) with $30(63.8 \%)$ respondents working fulltime. Fifteen (31.9\%) of the AHPs surveyed reported being the designated clinical supervisor of an AHA. The median (IQR) number of hours AHPs spent per day delegating to and supervising the clinical work of AHAs was $0.75(0.5$ to 1.0$)$ hours or $9.4 \%$ of their workday. Ten $(21.3 \%)$ respondents reported they spent more than 1 hour per day delegating to and supervising the clinical work of AHAs. There was no significant difference in number of hours spent per day delegating to and supervising the clinical work of AHAs by AHPs, either by discipline $(z=1.17, p=.24)$ or bywork setting $\left(\chi^{2}=6.05, p=.11\right)$. Of the AHPs surveyed, $42(89.4 \%)$ supervised one AHA only, and 4 (8.5\%) AHPs reported being responsible for supervising 2 AHAs. Survey data that related to available time and support for AHPs to supervise AHAs are described in Table 3. Thirty-six (76.6\%) AHPs reported that time available for supervision of AHAs was adequate, and 35 (74.5\%) AHPs reported being able to prioritize time within their workday for supervision of AHAs.

Table 3. Survey Data: Time and Support Available to AHPs

\begin{tabular}{|l|c|c|c|c|}
\hline \multicolumn{1}{|c|}{ Survey Data } & $\begin{array}{c}\text { Frequency (of } \\
\text { response) }\end{array}$ & Yes & No & Undecided \\
\hline Time available for supervision is adequate & 36 & $77 \%$ & $9 \%$ & $14 \%$ \\
\hline Able to prioritize time for supervision & 35 & $75 \%$ & $25 \%$ & 0 \\
\hline Has support of the organization to supervise AHAs & 44 & $77 \%$ & $23 \%$ & 0 \\
\hline Comfortable communicating issues related to AHAs & 45 & $100 \%$ & $0 \%$ & 0 \\
\hline AHA received regular formal supervision & 43 & $81 \%$ & $14 \%$ & $5 \%$ \\
\hline
\end{tabular}

Thirty (63.8\%) AHPs responded to a written response question that asked them to identify factors that affect AHP ability to prioritize time for clinical supervision of AHAs. These findings are summarized in Table 4 . While $74.5 \%$ of all AHPs surveyed reported they were able to prioritize time for supervision of AHAs, in this written response question, issues relating to time were identified as the major barriers to clinical supervision of AHAs.

Table 4: Themes Relating to Ability of AHPs to Prioritize Time for Clinical Supervision of AHAs

\begin{tabular}{|l|c|}
\hline Theme & Frequency \\
\hline Patient workload of AHP (hinders) & 16 \\
\hline AHP non-clinical duties (hinders) & 7 \\
\hline AHP staff shortages (hinders) & 6 \\
\hline AHP supervision of other staff (hinders) & 3 \\
\hline AHAs ability to come to clinical area when working across multiple wards (hinders) & 2 \\
\hline AHA availability (helps) & 2 \\
\hline AHA who prepares for supervision (helps) & 1 \\
\hline Relative importance of clinical supervision (helps) & 1 \\
\hline Blocking time out in advance (helps) & 1 \\
\hline AHA punctuality (helps) & 1 \\
\hline AHP part-time hours (hinders) & 1 \\
\hline AHA part-time hours (hinders) & \\
\hline
\end{tabular}

\section{Qualitative Results}

Eighteen participants (Seven, six, and five, respectively) attended 3 one-hour focus groups in different facilities within the health district. Transcribed focus group content was read multiple times to ensure an overall sense of the whole. Significant statements were noted and then used by the researchers to develop initial ideas and concepts, a process recommended by Graneheim and Lundman (2004). ${ }^{18}$ Specific sentences from the focus groups were taken and connected to several main categories that communicate a broader sense of meaning of the group as described by Creswell (2013, Online Video) as "capturing the essence of a phenomenon." ${ }^{19}$ This process is illustrated in Table 5.

Table 5: Preliminary Interpretation

\begin{tabular}{|l|l|l|l|}
\hline \multicolumn{1}{|c|}{ Highlighted Phrase } & \multicolumn{1}{c|}{ PB } & \multicolumn{1}{c|}{ SF } & Main Category \\
\hline $\begin{array}{l}\text { "They ask the AHAs a lot, to } \\
\text { absorb a lot of the } \\
\text { administrative role." }\end{array}$ & $\begin{array}{l}\text { Asks? } \\
\text { Excess, absorb }\end{array}$ & Absorb excess tasks & $\begin{array}{l}\text { Knowledge and role } \\
\text { differential }\end{array}$ \\
\hline $\begin{array}{l}\text { "I would have thought it } \\
\text { would be part of the course." }\end{array}$ & Assumed & $\begin{array}{l}\text { Need for knowledge at } \\
\text { undergraduate level }\end{array}$ & $\begin{array}{l}\text { Poor undergraduate } \\
\text { knowledge of AHAs }\end{array}$ \\
\hline
\end{tabular}




\begin{tabular}{|c|c|c|c|}
\hline $\begin{array}{l}\text { "Okay, for as long as it was, } \\
\text { I pretty much didn't use them } \\
\text { at all - I just kind of taught } \\
\text { myself." }\end{array}$ & $\begin{array}{l}\text { Knowledge of individual } \\
\text { AHAs experience }\end{array}$ & Ignorant but safe & $\begin{array}{l}\text { Under-developed AHP skill } \\
\text { in managing AHAs }\end{array}$ \\
\hline $\begin{array}{l}\text { "I don't think when I started, I } \\
\text { was given a list of what } \\
\text { AHAs were and weren't able } \\
\text { to do." }\end{array}$ & Lack of process & $\begin{array}{l}\text { Work out competencies and } \\
\text { knowledge as they go }\end{array}$ & $\begin{array}{l}\text { Lack of undergraduate } \\
\text { training in working with } \\
\text { AHAs }\end{array}$ \\
\hline $\begin{array}{l}\text { "My experience with AHAs is } \\
\text { different depending on } \\
\text { where you are working." }\end{array}$ & $\begin{array}{l}\text { Experience, Role } \\
\text { Clarification }\end{array}$ & $\begin{array}{l}\text { Context, Experience, } \\
\text { Expectation }\end{array}$ & Poor AHA role clarity \\
\hline $\begin{array}{l}\text { "My feeling is if AHAs are } \\
\text { going to be used more } \\
\text { frequently - you're } \\
\text { potentially leaving yourself } \\
\text { open more for indemnity } \\
\text { practices and should be } \\
\text { remunerated appropriately." }\end{array}$ & $\begin{array}{l}\text { May relate to idea that } \\
\text { knowledge about AHAs is } \\
\text { extra - so pay me extra }\end{array}$ & $\begin{array}{l}\text { Narrow focus relating to } \\
\text { feeling of not being in } \\
\text { control: "This is not what I } \\
\text { signed up for." }\end{array}$ & Supervision-load disconnect \\
\hline $\begin{array}{l}\text { "They kind of do things the } \\
\text { way they do it." }\end{array}$ & Culture & $\begin{array}{l}\text { Individualized scope of } \\
\text { practice }\end{array}$ & Personalization as a strategy \\
\hline $\begin{array}{l}\text { "If you have someone in that } \\
\text { role who knows exactly what } \\
\text { they are doing, it makes } \\
\text { everything achievable." }\end{array}$ & Increased therapy time & $\begin{array}{l}\text { Individual competency, } \\
\text { allocation of time }\end{array}$ & $\begin{array}{l}\text { Load=competence } \\
\text { continuum }\end{array}$ \\
\hline $\begin{array}{l}\text { "We can sign you off as } \\
\text { competent in certain tasks, } \\
\text { but you're still not allowed to } \\
\text { analyze." }\end{array}$ & Limitations imposed & $\begin{array}{l}\text { Hard barrier relating to } \\
\text { scope of practice }\end{array}$ & Boxing in \\
\hline $\begin{array}{l}\text { "And because she's capable } \\
\text { of making those decisions." }\end{array}$ & $\begin{array}{l}\text { Individual relationships } \\
\text { +skills + experiences }\end{array}$ & $\begin{array}{l}\text { Inference that this process is } \\
\text { not necessary }\end{array}$ & $\begin{array}{l}\text { Personality dependent } \\
\text { change }\end{array}$ \\
\hline $\begin{array}{l}\text { "Without that background, I } \\
\text { think you have to be a lot } \\
\text { more directive." }\end{array}$ & $\begin{array}{l}\text { Level of experience affects } \\
\text { the amount of time you } \\
\text { spend }\end{array}$ & $\begin{array}{l}\text { Increased time taken to be } \\
\text { prescriptive/to mitigate risk }\end{array}$ & $\begin{array}{l}\text { Load-competency } \\
\text { dependent change }\end{array}$ \\
\hline
\end{tabular}

Following this preliminary interpretation, the researchers reviewed the identified main categories through a dialogue, which considered the original research questions and sought to probe more deeply to further develop an understanding of the position taken by the focus group participants. ${ }^{20}$ The result of this strategy is a categorization to themes (see Table 6). Prior to these themes being accepted, focus group participants were invited to validate these themes from their focus group experience. This member checking did confirm strong identification with the identified themes and has served to increase confidence in the trustworthiness of our findings. ${ }^{21}$

Table 6: Categorization of Themes: Four Main Categories Emerged From Focus Group

\begin{tabular}{|l|l|}
\hline \multicolumn{1}{|c|}{ Main Category } & \multicolumn{1}{c|}{ Theme } \\
\hline Knowledge and role differential & AHA perspective \\
Poor undergraduate knowledge of AHAs & \\
\hline $\begin{array}{l}\text { Under-developed AHP skills in managing AHAs } \\
\text { Lack of AHP training in working with AHAs } \\
\text { Poor AHA role clarity }\end{array}$ & Experience in the workplace \\
\hline $\begin{array}{l}\text { Supervision-load disconnect } \\
\text { Personalization as a strategy } \\
\text { Load-competence continuum }\end{array}$ & The underprepared AHP \\
\hline
\end{tabular}




\begin{tabular}{|l|l|}
\hline Boxing in & AHP supervision strategies \\
Personality dependent change & \\
Load-competence dependent change & \\
\hline
\end{tabular}

\begin{abstract}
AHP Perspective
This perspective is based on a commonality of being graduate health professionals, whose knowledge, skills, attitudes, and behavior relate to attaining current best practice and contrasts with the training and roles of AHAs. ${ }^{22,23}$ While AHAs also strive toward attaining current best practice, focus group statements such as "the past experience of this AHA; [and] I don't even know what you've done" illustrate both the variability of their educational background and AHP lack of understanding of AHA training. A focus group statement that "I don't think when I started, I was given a list of what AHAs were and weren't able to do," illustrates this AHP perspective as one which encapsulates AHPs in a common structure and understanding and is derived from their common educational background but does not extend to an understanding of AHA training, skills, and roles.
\end{abstract}

\title{
AHP Experience in the Workplace
}

AHP focus group feedback did not describe time taken to supervise AHAs as being onerous. Several participants detailed work situations involving unstructured communication or "touching base" between AHP and AHA. These communications were deemed successful by AHPs and described by one focus group participant as "occurring regularly throughout the day." However, when discussion focused on AHPs supervising greater numbers of AHAs, there were some expressions of concern that "supervision would take more time." Clinicians were concerned that supervision would result in "increased AHP distance from the patient," described by one participant as "not being able to keep up to date with what the patients are doing." AHP feedback was also supportive of the value of AHAs in the workplace, demonstrated through comments such as "I find them extremely useful" and "our AHA is very capable." However, focus group comments such as "my experience with AHAs is different depending on what section you are working in" and "it depends on how competent they are," indicated that AHP support for the value of AHAs can also vary depending on work setting and perceived competence of the AHA. A further focus group comment that "it takes time to know their capabilities," and "my AHA doesn't know what your AHA knows," reinforced the idea that variability of AHA training and experience influences AHP judgment as to the value of AHAs.

\section{The Underprepared AHP}

Focus group feedback indicated that AHPs are underprepared to supervise and delegate tasks to AHAs. Focus group comments such as "we haven't trained as AHAs, we don't know what they know," illustrated an awareness of the differences in AHP and AHA education as well as a lack of knowledge of AHA training, skills, and roles. Other focus group statements, such as "when you go to a new health service you just kind of find out for yourself" and "I just kind of taught myself" further illustrated that the gap in AHP understanding about attaining supervision skills and knowledge requires that AHPs create a new way of understanding how to supervise and delegate to AHAs.

\section{AHP Supervision Strategies}

Focus group feedback indicated that when supervising AHAs and Illawarra Shoalhaven Local Health District AHPs added structure in two principal ways. First, in the absence of knowledge of AHA training and educational background, AHPs accentuated the importance of personal AHA attributes and skills. Focus group statements such as "an AHA that we've employed who used to be a hairdresser and has an incredible ability to build rapport, has become one of the best AHAs we've ever had" and "I think it depends on their personality and what their confidence level is," are indicative of this approach. Second, AHPs attempted to add structure when supervising AHAs by varying the degree to which they delegate to AHAs based on their perception of AHA competence. We have used the term "load-competence continuum" in our focus group interpretation to describe how AHPs delegated more to an AHA who they perceived has greater competence. At one end of this load-competence continuum, AHAs are underutilized. Focus group statements, such as "I pretty much didn't use them at all" and "sometimes when teams are unsure what to delegate, the AHA can be under-utilized and the team is very frustrated when they see a resource not being used," illustrated the strategy. At the other end of this continuum, statements, such as "when I think back, I would have over trusted my AHA," demonstrated evidence of inappropriate delegation.

\section{DISCUSSION}

A key finding of this study was that AHPs reported they had adequate time to supervise AHAs. The descriptive analysis of quantitative data demonstrated a lack of AHP knowledge of AHA training, skills, and roles as well as deficiencies in AHP clinical supervision skills. These gaps in skills and knowledge resulted in AHPs being unprepared for supervising AHAs. While analysis of both quantitative and qualitative data found that AHPs value AHAs in the workplace, the findings also indicated that support for the value of AHAs can vary depending on work setting and perceived competence of the AHA. Furthermore, given that both data sets included a mix of experienced and less experienced AHPs, the findings indicated that deficiencies in supervision skills and lack of knowledge of AHA training, skills, and roles was not restricted to newer 
graduates. These findings of current supervision strategies used by AHPs demonstrated that they are an unsatisfactory blueprint for optimal utilization of the AHA workforce. This study was also important because it was the first to quantify AHP supervision and delegation to AHAs as a proportion of their workday. Of an AHP's workday, $10 \%$ was spent delegating to and supervising the clinical work of AHAs. While 75\% of AHPs reported they had adequate time to prioritize supervision of AHAs, survey data also identified that issues relating to time were the major barriers to prioritizing time for clinical supervision of AHAs. The incongruence of these findings may be explained by the high proportion (89.4\%) of AHPs who supervise and delegate to one AHA only. These findings may also limit the applicability of this study's findings to other work settings where different AHP-AHA staff mixes occur.

\section{A Solution}

The findings of this study were used to support the premise that improving AHP knowledge of AHAs and upgrading AHP clinical supervision skills would result in more effective supervision and delegation to AHAs.

\section{Improved AHP Knowledge}

AHPs require better knowledge of AHA training, skills and roles. The findings supported greater use of appraisal tools, such as the Calderdale Framework, a 7-step, clinician-led process used to improve the way a healthcare team works. ${ }^{24}$ This framework, which can be used for planning and implementing AHA roles, has been found to result in better role sustainability and more effective and efficientuse of AHAs. ${ }^{25}$ In addition, making online training programs would be proposed for how to work effectively with AHAs, which are currently available in New South Wales (NSW) through the NSW government Health, Education, and Training Institute (HETI), mandatory and assessable for those AHPs responsible for supervising AHAs. ${ }^{26}$

\section{Improved AHP Skills}

Supervision of an AHA is a multifaceted task, requiring a broad range of skills, which extend beyond that of clinical expertise..$^{13}$ Recognition of the need for these skills has been identified as important for AHPs. $1,3,25$ Skills in the use of "reflective practice," more commonly the domain of AHPs because they can encompass clinical reasoning, should be incorporated into the supervision of AHAs. ${ }^{25}$ Reflective practice within supervision can ideally be used to clearly define the relationship between AHP and AHA and can be a suitable focus to consider multiple perspectives, ask questions, and challenge assumptions. ${ }^{27,28}$

\section{Improved AHA Award Structure}

The AHA award structure in NSW was updated in 2018 and now recognizes academic attainment through both salary and scope of practice. ${ }^{9}$ This improvement in structure will help AHPs to both supervise and delegate to AHAs and has been included as a third critical factor contributing to effective use of AHAs in allied health teams. Figure 2 illustrates the contribution of these three factors in facilitating effective use of AHAs in allied health teams.

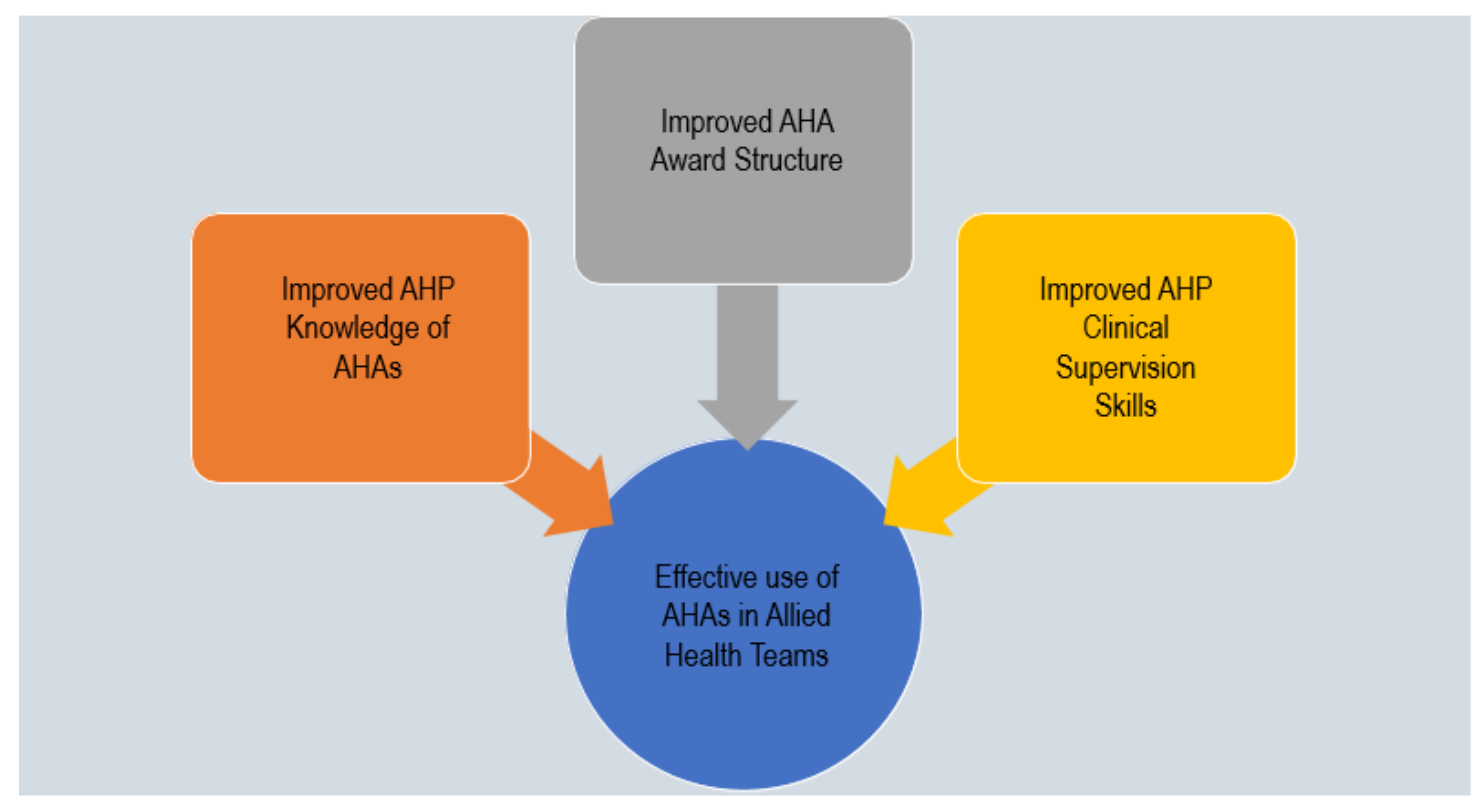

Figure 2. Effective use of AHAs in Allied Health Teams 


\section{Limitations of the Study}

The survey tool used in this study was self-developed and was not validated, which may limit transferability of the data and outcomes to other health settings. A further limitation was that this study used one single health service. However, the findings may reflect the experience of AHPs in other NSW local health districts in which there was similar education for AHPs and in which similar training and award structures apply to AHAs.

\section{CONCLUSION}

This research presented evidence that AHPs in this local health district have adequate time to supervise AHAs, but lack knowledge of AHA training, skills, and roles and that this gap in understanding is pivotal to the way that these two groups interact in the workplace. More innovative approaches to improve AHP skills in supervising AHAs will better optimize the use of this important allied health workforce.

\section{Competing Interests}

None declared

\section{REFERENCES}

1. Health Workforce Australia (2014) Assistants and support workers: workforce flexibility to boost productivity. http://www.hwa.gov.au/sites/default/files/HWA\%20Assistants\%20and\%20Support\%20Work ers_Full\%20report.pdf

2. Kuipers P, Hurwood A \& McBride L (2015). Audit of allied health assistant roles: Suggestions for improving quality in rural settings. Aust Journal of Rural Health, 23, 185-188

3. Nancarrow S, Moran A \& Sullivan R (2015). Mechanisms for the effective implementation of an allied health assistant trainee: a qualitative study of a speech language pathology assistant. Aust Health Rev, 39, 101-108.

4. Munn Z, Tufanaru C \& Aromataris E (2013). Recognition of the health assistant as a delegated clinical role and their inclusion in models of care: a systemic review and meta- synthesis of qualitative evidence. Int Journal of Evidence-Based Healthcare, 11, 3-19.

5. Somerville L, Davis A, Elliott A, Terrill D, Austin N \& Phillip K (2015). Building allied health workforce capacity: an approach to workforce innovation. Australian Health Review, 39, 264- 270.

6. Somerville L, Davis A, S Milne, Terrill S \& Phillip K (2017). Exploration of an allied health workforce redesign model: quantifying the work of allied health assistants in a community workforce. Australian Health review, 42 (4), 469-474.

7. New South Wales Ministry of Health, Allied Health Assistant Framework, 2013. http://www0.health.nsw.gov.au/policies/gl/2013/GL2013_005.html

8. Lewis R \& Kelly S (2015) Education for healthcare clinical support workers. Nursing Standard, 30,15, 3841.

9. NSW Health Service allied health assistants (state) award (2018). https://www.health.nsw.gov.au/careers/conditions/Awards/hsu-he-technical.pdf

10. Victoria Health (2012). Supervision and delegation framework for alliedhealth https://www.health.nsw.gov.au/careers/conditions/Awards/hsu-he-technical.pdf assistants.

11. Allied Health Professions Office of Queensland (2016). Allied health assistant framework. www.health.qld.gov.au/ahwac/default.asp

12. Lin I \& Goodale B (2006). Improving the supervision of therapy assistants in Western Australia: The Therapy Assistant Project (TAP), Rural and Remote Health, 6:479 (online).

13. Moran $A$, Nancarrow $S$ \& Enderby $P(2015)$. Mechanisms to enhance the effectiveness of allied health and social care assistants in community-based rehabilitation services: a quantitative study. Health and Social Care in the Community, 23 (4), 389-398.

14. Schmidt D (2013). Supervising Allied Health Assistants: A concerning Skill gap in Allied Health Professionals. Journal of Allied Health, 42(4):243-246.

15. Cresswell J \& Plano Clark V (2011). Designing and conducting mixed method research (2nd Edition) Sage Press, Los Angeles.

16. Vandermause $\mathrm{R}$ (2008).The poiesis of the question in philosophical hermeneutics: Questioning assessment practices for alcohol use disorders, Int J of Qualitative Studies on Health and Well-being, 2008, 3 (2), 68-76.

17. Fitzpatrick $S$ (2016). Clinical Supervision in Allied Health: A process and model for Policy Development and Implementation. An Exegesis presented in fulfilment of the requirements for the degree of Doctor of Health Science at Charles Sturt University.

18. Graneheim U \& Lundman K (2004). Qualitative content analysis in nursing research: concepts, procedures and measures to achieve trustworthiness. Nurse Education Today, (2):105-112.

19. Creswell J (viewed 30 $0^{\text {th }}$ April 2016). (Video) What is Mixed Method Research. Online video, University of Nebraska- 
Lincoln, published Spring 2013.

20. Higgs J, Cherry N, Maklin R \& Ajjawi R (Eds.) (2010). Researching Practice: A discourse on Qualitative Methodologies, Sense Publishers.

21. Patton M (2015). Qualitative Research and Evaluation Methods (4th Edition) Integrating Theory and Practice, Sage Publications.

22. Grace S \& Trede F (2011). Developing professionalism in physiotherapy and dietetics students in professional entry courses. Studies of Higher Education, 1-14.

23. Richardson B, (1998). Professional Development: Professional Socialisation and Professionalism. Physiotherapy, 85:9.

24. Smith R \& Duffy J (2010). Developing a competent and flexible workforce using the Calderdale Framework, Int J of Therapy Rehabilitation, 2010, 17(5), 254-262.

25. Nancarrow S, Moran A, Wiseman L, Pighills A \& Murphy K (2012). Assessing the implementation process and outcomes of newly introduced assistant roles: aqualitative study to examine the utility of the Calderdale Framework as an appraisal tool. J of Multidisc Healthcare, 5, 307-317.

26. https://www.heti.nsw.gov.au

27. Fitzpatrick S, Smith M and Wilding, Quality allied health clinical supervision policy in Australia: a literature review, Aust Health Rev, 2012, 36, 461-456.

28. Von Zweck C, The art of clinical supervision for Occupational Therapists. Occupational Therapy Now, 2007, 9(6), 1013. 